\title{
Risk Factor Evaluation of Musculoskeletal Symptoms for Guards
}

\author{
Kyung-Sun Lee ${ }^{1}$, Inseok Lee ${ }^{2}$, Hyunjoo Kim ${ }^{3}$, Kyunghee Jung-Choi ${ }^{4}$, \\ Jinwook Bahk, ${ }^{5}$ Myung-Chul Jung ${ }^{1}$ \\ ${ }^{1}$ Department of Industrial and Information Systems Engineering, Ajou University, Suwon, 443-749 \\ ${ }^{2}$ Department of Safety Engineering, Hankyong National University, Anseong, 456-749 \\ ${ }^{3}$ Department of Occupational and Environmental Medicine, Dankook University College of Medicine, Cheonan, 330-714 \\ ${ }^{4}$ Department of Preventive Medicine, Ewha Womans University School of Medicine, Seoul, 120-750 \\ ${ }^{5}$ School of Public Health, Seoul National University, Seoul, 151-742
}

\begin{abstract}
Objective: The objective of this study was to evaluate a work of guards, using an ergonomic method(work analysis and posture analysis). Background: Most studies about guards were conducted in the field of medical, problems of shift, and the physical problems of old workers and social problems. But, guards consist of vulnerability group so it needs an ergonomic research in musculoskeletal disorders. Method: A head of an ergonomic estimation was work analysis(determination of combined task, work tool, work time and frequency of combined task) and posture analysis(upper body and lower body) of workers based on the video. Results: The result showed that combined task of guards was classification of patrolling, security, cleaning and waiting. The security indicated the highest ratio in the work time of combined tasks. The results of posture analysis for guards indicated high value in neutral. But, lower arm indicated high value in bending(left: $59 \%$, right: 50\%). Conclusion: The results of ergonomic methods indicated that guards' physical work load was not high during work, but comfortable work environment would be required for old guards. Application: If an ergonomic rule can be integrated into existing work environments, the risk of occupational injuries and stress will be reduced.
\end{abstract}

Keywords: Musculoskeletal symptoms, Guards, Work Analysis, Posture Analysis

\section{Introduction}

취약집단은 건강관련 문제 발생의 위험이 높은 집단으로 부정적 건강결과에 대한 상대적인 위험비나 민감도가 높은 집단으로 정의한다(Aday, 1993; Sebastian, 1999). Lee et al.(2006)은 산재다발집단, 법 - 제도 관리취약집단, 사회 적 취약집단을 산재취약집단으로 구분한다. 이 중 중소규모 사업장은 산재 발생 정도 및 법제도적 보호에서 취약성을 지니고 있으며, 사회적 취약집단으로는 고령 및 여성 작업자

\author{
들로 분류한다. \\ 이 중 고령 작업자의 신체적 작업수행능력은 운동기능 \\ (Motor Function), 지각기능(Perceptual Function), 인지적 \\ 기능(Cognitive Function) 그리고 생리적 기능(Physiology \\ Function)에서 청년층에 비해 현저히 기능의 저하를 보인다 \\ (Menz et al., 2003; Haight, 1993; Wegmen and McGee, \\ 2004). 이처럼 신체적 작업수행능력 기능이 저하를 나타내 \\ 는 고령 작업자는 건강위험도가 상대적으로 높은 취약계층 \\ 으로 분류된다. \\ 이들 고령자의 경제활동참가율을 살펴보면, 50 세 이상자의
}

Corresponding Author: Myung-Chul Jung. Department of Industrial and Information Systems Engineering, Ajou University, Suwon, $443-749$. Phone: 031-219-2981, E-mail: mcjung@ajou.ac.kr

Copyright@2011 by Ergonomics Society of Korea(pISSN:1229-1684 eISSN:2093-8462). All right reserved. 
경제활동참가율은 연령이 증가하면서 감소하는 경향을 보인 다. 하지만 60 64세까지 남성의 경제활동참가율은 $70 \%$ 에 가까이 유지되며, 65 세 이상에서도 약 $40 \%$ 의 경제활동참가 율을 보인다(Korea Ministry of Labor, 2009). 이렇듯 고령 작업자들의 경제활동참가율은 높게 분포되어 있다. 이들 고 령 작업자들에 대한 Korea Ministry of Labor(2006)의 경제활동인구조사 부가조사(고령층) 결과에 의하면, 55 세 이상 고령 작업자의 주된 취업 분야는 서비스업종으로 높은 비중을 차지하고 있다. 보다 구체적으로 취업직종을 살펴보 면, 50대는 상점판매 및 관리인이 가장 많았으며 60대는 상점판매 및 관리인, 청소원, 경비 및 건물관리인 순이었다 (Korea Employment Information Service, 2004).

서비스업종에서 고령 작업자의 직종별 인간공학 분야 연구 동향을 살펴보면, 음식서비스직 (Ono et al., 1997; Messing and Kilbom, 2001; Jung-Choi et al., 2004; Ahn et al., 2006; Choi et al., 2007), 청소직(Hagner and Hagberg, 1989; Kumar et al., 2005; Woods and Buckle, 2005; Lee et al., 2007; Myong et al., 2008; Kumar and Kumar, 2008), 경비직 (Kim et al., 1999) 등에 대한 작업특성 파악 연구가 진행되었다. 이 중 근골격계질환의 특성을 파악한 연 구 또한 활발히 이루어지고 있다.

하지만 50대와 60 대의 고령 작업자가 많이 분포되어 있 는 경비 및 건물관리인에 대한 인간공학 분야의 연구는 찾아 보기 힘들다. 선행 경비 및 건물관리인에 대한 연구를 살펴 보면, Kang et al. (2002)은 아파트관리업무 종사자(경비직: $76.7 \%$, 시설직: $23.2 \%$ )의 고혈압 관리 효과 및 요인 평가 를 실시하여 교대근무의 문제를 이야기 하고 있으며, 효과적 인 혈압 관리를 위하여 스트레스, 교대근무 형태의 직업적인 요소에 대하여 고려해야 한다고 하였다. Kim et al.(1999) 은 아파트 경비원의 건강상태와 관련요인을 파악하기 위한 연구를 수행한 결과, 신체화 증상에 대한 항목 중 허리가 아 프다 $(47 \%)$ 는 작업자가 가장 높은 비율을 나타냈고 근육통 또는 신경통이 있다고 응답한 작업자 역시 $45.1 \%$ 로 높게 나타났다. 하지만 이는 육체적인 작업의 강도에 의한 것이 아니라 연령이나 경비 근무자간의 신체화의 차이일 수도 있다고 말하고 있다. $\operatorname{Kim}(2008)$ 은 민간경호원의 스트레스 유발요인에 관한 연구를 수행하였으나, 신체적인 스트레스에 대해서는 언급하고 있지 않다.

이처럼 경비 및 건물관리인에 대한 연구는 의학적 관리 차 원의 연구가 대부분이며, 교대근무에 문제성과 고령 근무자 가 가지고 있는 신체적인 문제 혹은 여러 가지 사회적인 문 제에 대해서만 언급되고 있다. 하지만 산재취약 계층인 고령 자가 많이 종사하고 있는 경비직 및 건물관리 업종은 인간공 학적인 연구를 수행해야 할 필요성을 지니고 있다.

따라서 본 연구의 목적은 경비직 작업자를 상으로 현장조
사 및 동영상 분석을 기반으로 작업환경 평가 및 작업자 평 가 등의 인간공학적 연구를 수행하는 것이다. 본 연구에서는 작업분석, 자세분석, 주관적 불편도 분석을 통하여 인간공학 적 평가를 실시하였다.

\section{Method}

\subsection{Research subjects}

조사대상자는 경기도 소재의 아파트에서 근무하는 경비직 작업자 2 명과 충청도 소재의 대학병원에서 근무하는 경비직 작업자 2 명으로, 총 4 명을 대상으로 현장조사 및 동영상 분 석을 실시하였다. 조사대상자는 모두 남성으로 평균 연령은 64.5( \pm 1.9$)$ 세로 고령 작업자에 속하였다. 조사대상자의 선 정은 작업분석의 오류를 최소화하기 위하여 조사대상 사업 장에서 가장 숙련된 작업자를 선택하였다.

\subsection{Research methods}

인간공학적 평가는 1) 작업분석(Working analysis) 과 2) 자세분석(Posture analysis)을 실시하였다. 작업분석과 자 세분석을 위한 동영상 촬영은 오전 9시부터 오후 5시까지 진행하였다. 작업자는 가능한 촬영을 의식하지 않고 자연스 럽게 평상 시의 작업과 동일하게 작업에 임하도록 교육을 실시하였으며, 관찰자 역시 작업자의 작업에 방해되지 않는 범위에서 촬영을 실시하였다. 동영상 촬영은 가능한 작업자 의 전신과 작업반경이 모두 촬영되도록 하였으며 이동 작업 시에는 관찰자 역시 함께 동행하며 촬영을 실시하였다.

작업분석을 통하여 단위 작업 정의, 작업도구 및 작업대 분석, 단위 작업별 평균작업시간 및 하루 8 시간 기준 동안의 총 작업시간을 산출하였다. 단위 작업 정의는 작업자 인터뷰 내용과 현장조사 시 촬영한 동영상 자료를 기반으로 관찰자 간의 협의를 통하여 정의하였다. 작업도구 및 작업대 분석은 작업 중 사용하는 작업도구에 관하여 치수정보를 수집하여 정리하였다. 단위 작업별 평균작업시간은 작업자별 촬영된 동영상 시간 중에 발생하는 시간을 초 단위로 산출한다. 초 단위로 산출된 단위 작업의 빈도 또한 함께 분석하였다. 동 영상 기반으로 산출된 단위 작업당 작업시간은 다시 하루 8시간 기준으로 작업시간을 환산하였다. 8시간 기준 단위 작업별 작업시간의 환산은 480 분 $\times$ 평균단위 작업시간(분) / 총작업시간(분)으로 계산된다.

자세분석에서 사용할 동영상 샘플은 촬영된 동영상 샘플 들 중에서 가장 가림현상이 적고, 촬영상태가 좋다고 판 단되는 샘플 1 개를 대표로 선정하였다. 자세분석은 기존의 
Ovako working posture analyzing system(OWAS) 과 같 은 macro 자세분석 방식을 선택하였고 이는 하루 근무 중 발생하는 자세에 대한 직관적인 이해가 가능한 장점이 있다 (Karhu et al., 1977). 상체 자세분석은 목, 위팔, 아래팔, 손, 허리에 대하여 중립, 굴곡, 회전, 판단불가(가림현상)의 항목 으로 구분하여 분석을 실시하였다. 하지 자세분석은 서기, 무릎굽혀서기, 걷기, 앉기, 기타, 판단불가(가림현상) 항목으 로 구분하여 분석을 실시하였다. 본 연구에서는 제조업 평가 에서 요구하는 정확성보다는 정형화되지 않은 직업의 특성 상 일반성을 강조하여, 위팔 굴곡은 $90^{\circ}$ 이상 그리고 $90^{\circ}$ 이하로(Keyserling, 1986; 1992) 구분하였으며, 허리는 $45^{\circ}$ 이상과 $45^{\circ}$ 이하로 구분하였다(Froeman and Troup, 1987; Genaidy et al., 1993). 손, 목 그리고 아래팔 굴곡 은 중립 자세 $\left(0^{\circ}\right.$ 또는 직선 $)$ 를 기준으로 평가하였다. 하지는 Grandjean et al. (1977), Baty et al. (1987), Ryan(1989), Keyserling (1990), 그리고 Lee et al.(2002)의 연구를 기 초로 서기, 무릎굽혀서기, 걷기, 앉기, 기타, 판단불가(가림현 상) 항목으로 구분하여 분석하였다. Table 1 은 자세분석에 서 사용한 각 체절별 평가 기준을 나타낸다. 이와 같은 자 세분석을 통하여 단위 작업별 가장 빈번히 발생하는 대표 자세를 얻을 수 있으며, 상체 자세에 있어서는 부적절한 자 세가 가장 많이 발생한 체절에 대한 정보를 획득한다. 자세 분석은 분석자간의 에러를 최소화 하기 위하여 작업동영상 분석에 숙련된 분석자가 분석을 실시하였으며, 자세분석의 분석주기는 1 초에 1 프레임 간격으로 하였다(Andrews and Callaghan, 2003). 자료의 분석과 편집은 Adobe Premiere $\mathrm{V} 6$ 를 사용하였다.

Table 1. Posture analysis criteria

\begin{tabular}{l|l|l}
\hline Body & $\begin{array}{c}\text { Segment/ } \\
\text { Classification }\end{array}$ & \multicolumn{1}{c}{ Criteria } \\
\hline \multirow{4}{*}{$\begin{array}{l}\text { Upper } \\
\text { Body }\end{array}$} & Neck & $0^{\circ}$ or Straight \\
\cline { 2 - 3 } & Upper arm & Below $90^{\circ}$, More than $90^{\circ}$ \\
\cline { 2 - 3 } & Lower arm & $0^{\circ}$ or Straight \\
\cline { 2 - 3 } & Hand & $0^{\circ}$ or Straight \\
\cline { 2 - 3 } & Trunk & Below $45^{\circ}$, More than $45^{\circ}$ \\
\hline \multirow{4}{*}{$\begin{array}{l}\text { Lower } \\
\text { Body }\end{array}$} & Standing & Feet are only supported by the ground \\
\cline { 2 - 3 } & $\begin{array}{l}\text { Standing with } \\
\text { bending knee }\end{array}$ & $\begin{array}{l}\text { Feet are supported by the ground } \\
\text { with bending knee }\end{array}$ \\
\cline { 2 - 3 } & Walking & Walking more than two steps \\
\cline { 2 - 3 } & Leaning & $\begin{array}{l}\text { Part of the body mass is supported } \\
\text { by the external object }\end{array}$ \\
\cline { 2 - 3 } & Sitting & $\begin{array}{l}\text { Body mass is mainly supported by } \\
\text { ischial tuberosity }\end{array}$ \\
\cline { 2 - 3 } & Etc. & Kneeling or squatting \\
\hline
\end{tabular}

\section{Results}

\subsection{Work analysis}

경비직 작업자는 경비실 내에서 정적인 좌식상태로 상황 을 보며 대기하고, 각종 민원을 처리하는 업무를 주로 수행 하며, 필요 시 간헐적으로 청소 업무를 하기도 한다. 또한 택배 및 우편물을 수령하거나 부가적인 업무도 수행하고 있다. 경비직 작업자는 사업장의 형태에 따라 근무 형태가 약간의 차이는 보이지만 크게 다르지 않다. 경비직 작업자의 실제 근무시간은 하루 24 시간 근무로서 약 1 시간의 식사시 간과 짧게는 3 시간에서 길게는 5 시간까지 근무 중 가수면 시간이 있다. 경비직 작업자들의 작업분석 결과를 토대로 단위 작업을 순찰, 상황, 청소, 대기로 구분하였다(Table 2).

Table 2. Combined task of Guards

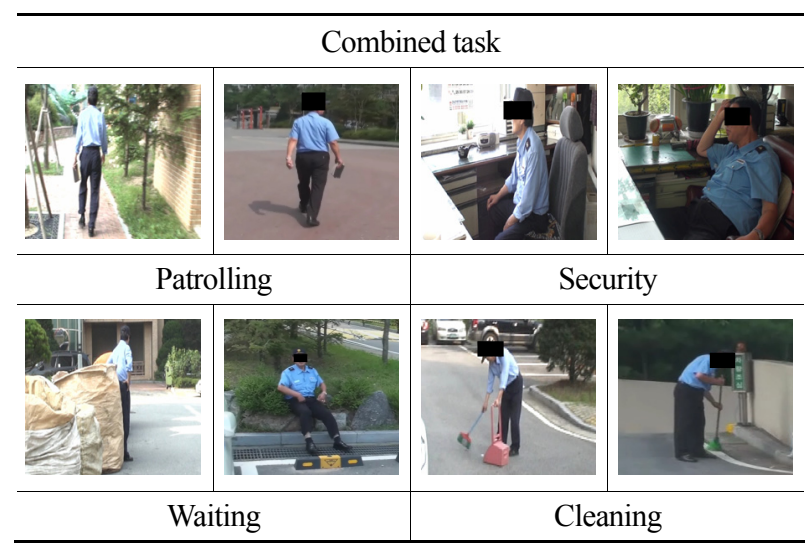

순찰 작업은 근무시간 중 일정한 시간 간격으로 해당 작업 자에게 할당된 순찰 구역을 순회하며 지역의 이상 유·무를 파악하는 작업이다. 순찰 작업의 시점은 밖으로 나가기 위해 경비실 문을 여는 시점으로 정의하였다. 일반적으로 순찰 작업 시 사용하는 도구로는 순찰일지가 있으며, 야간에는 총길이 $54.5 \mathrm{~cm}$, 손잡이 길이/둘레 $10.5 / 12 \mathrm{~cm}$, 무게 $1.1 \mathrm{~kg}$ 에 상응하는 야광봉을 들고 순찰 업무를 수행한다. 상황 작 업은 경비실 내에서 상황을 보면서 대기하는 작업으로서 아 파트의 경우 택배 및 우편물 대리수령, 단지 안내, 출입자 차단 등의 부가적인 업무를 동반하며, 병원의 경우 환자 보 호, 건물 안내, $\mathrm{CCTV}$ 상황, 안내방송 등의 업무를 함께 수 행한다. 상황 작업의 시점은 경비실 안으로 들어가기 위해 외부에서 경비실 문을 여는 시점으로 정의하였다. 청소 작업 은 특별히 정해진 구역이 할당되어 있지는 않지만 순찰 업 무 중 주변에 발생한 쓰레기와 쓰레기장 혹은 분리수거장 주변을 수시로 정리하며 청소하는 작업이다. 청소 작업의 시 
점은 작업자가 청소도구를 들고 경비실 밖을 나가는 시점 으로 정의하였다. 청소 작업 시 작업자가 사용하는 작업도 구로는 총길이 $163 \mathrm{~cm}$, 봉길이 $115 \mathrm{~cm}$, 손잡이 둘레 $8 \mathrm{~cm}$, 무게 $1.3 \mathrm{~kg}$ 의 대빗자루를 사용하며, 봉길이 $75 \mathrm{~cm}$, 손잡이 둘레 $9 \mathrm{~cm}$, 빗자루 솔의 너비 $27 \mathrm{~cm}$, 무게 $0.2 \mathrm{~kg}$ 에 상응하 는 소빗자루를 사용한다. 이외에도 쓰레받기 (총길이 $65 \mathrm{~cm}$, 폭 $28 \mathrm{~cm}$, 손잡이 둘레 $8 \mathrm{~cm}$, 무게 $2.1 \mathrm{~kg}$ ) 와 집게 (총길이 $60 \mathrm{~cm}$, 너비 $2.6 \mathrm{~cm}$, 손잡이 사이의 각도 $16^{\circ}$, 무게 $0.1 \mathrm{~kg}$ ) 를 사용하였다. 대기 작업은 앞서 정의한 순찰, 상황, 청소 작업 도중 작업 이외에 발생하는 동작을 말한다. 이는 거주 자의 분리수거를 도와주고 주변 정리를 하기 위해 분리수거 장에서 대기하는 작업 등을 말한다.

작업시간 및 자세분석을 위한 동영상 촬영은 사업장 사정 에 의하여 경기도 소재 아파트 2명의 작업자만을 대상으로 실시하였다. 작업자 1 의 동영상 촬영시간은 총 383 분이며, 작업자 2는 364 분이었다. Table 3 은 촬영된 동영상에 대 한 단위 작업별 작업시간(분)과 작업빈도(횟수)를 산출하고 이를 식 1을 사용하여 하루 8시간 작업 기준으로 단위 작업

Table 3. Work time(min) and frequency(number) of combined task of Guards

\begin{tabular}{l|r|r|r|r|c|c}
\hline \multirow{2}{*}{$\begin{array}{c}\text { Combined } \\
\text { task }\end{array}$} & \multicolumn{2}{|c|}{ Worker 1 } & \multicolumn{2}{c|}{ Worker 2 } & \multicolumn{2}{c}{$\begin{array}{c}\text { Mean } \\
\text { (Standard Deviation) }\end{array}$} \\
\cline { 2 - 7 } & \multicolumn{1}{c|}{$\mathrm{F}$} & \multicolumn{1}{c|}{$\mathrm{T}$} & \multicolumn{1}{c|}{$\mathrm{F}$} & \multicolumn{1}{c}{$\mathrm{T}$} & $\mathrm{F}$ & $\mathrm{T}$ \\
\hline Patrolling & 6 & 48 & 3 & 22 & $4.5(2.6)$ & $34.7(18.4)$ \\
\hline Security & 19 & 282 & 20 & 302 & $19.3(0.7)$ & $291.7(13.9)$ \\
\hline Cleaning & 18 & 131 & 22 & 123 & $19.9(3.4)$ & $127.2(6.1)$ \\
\hline Waiting & 13 & 19 & 21 & 34 & $16.7(6.0)$ & $26.3(10.6)$ \\
\hline Total & 55 & 480 & 66 & 480 & 60 & 480 \\
\hline
\end{tabular}

*F: Frequency, T: Time
별 작업시간과 작업빈도를 나타낸 것이다.

하루 8시간 근무 기준 경비직 작업자는 순찰 작업을 34.7 분 동안 4.5회 실시하며, 상황 작업은 291.7 분 동안 19.3 회 실시한다. 청소 작업의 경우, 8시간 근무 기준으로 127.2 분 동안 19.9회 실시하며, 대기는 26.3분 동안 16.7 회 발생 한다.

\subsection{Posture analysis}

자세분석은 2 명의 작업자를 통해 촬영된 동영상을 기반 으로 실시하였다. 분석에 사용한 각 샘플의 시간은 Table 4 와 같다.

Table 4. Sample time(Sec) of combined task

\begin{tabular}{l|c|c|c}
\hline Combined task & Worker 1 & Worker 2 & $\begin{array}{c}\text { Mean } \\
\text { (Standard Deviation) }\end{array}$ \\
\hline Patrolling & 110 & 229 & $170(84.1)$ \\
\hline Security & 507 & 297 & $402(148.5)$ \\
\hline Cleaning & 282 & 101 & $192(128.0)$ \\
\hline Total & 899 & 624 & 763.0 \\
\hline
\end{tabular}

경비직 작업자가 수행하는 전체 작업에 대한 작업 자세 분포는 Table 5 와 같다. 경비직 작업자의 각 체절별 자세 발 생 비율과 일일 근무시간 중 발생시간을 분석해본 결과, 하 루 8시간 근무 중 좌측 아래팔은 $59 \%$ 그리고 우측 아래팔 은 $50 \%$ 의 굴곡 비율을 나타냈다. 아래팔을 제외한 나머지 상체 부위는 일일 근무시간 중 중립 자세를 취하는 분포가 구부림, 비틂, 구부림과 비틂 자세 보다 높게 분포하였다. 하 지 자세의 경우에는 일일 근무시간 중 $48 \%$ 를 앉기 자세를 취하고 있으며, 걷기가 $33 \%$ 의 분포를 차지하였다(Table 5).

Table 5. Work posture distribution(\%) of guards

\begin{tabular}{|c|c|c|c|c|c|c|c|c|}
\hline \multicolumn{2}{|c|}{ Upper extremity } & Neutral & \multicolumn{2}{|c|}{ Bending } & Twisting & Bending \& Twisting & Invisible & Total \\
\hline \multicolumn{2}{|l|}{ Neck } & 53 & \multicolumn{2}{|c|}{26} & 12 & 2 & 7 & 100 \\
\hline \multirow{2}{*}{ Upper arm } & Left & 54 & 39 & - & - & - & 7 & 100 \\
\hline & Right & 52 & 41 & - & - & - & 7 & 100 \\
\hline \multirow{2}{*}{ Lower arm } & Left & 33 & \multicolumn{2}{|c|}{59} & - & - & 8 & 100 \\
\hline & Right & 43 & \multicolumn{2}{|c|}{50} & - & - & 7 & 100 \\
\hline \multirow{2}{*}{ Hand } & Left & 55 & \multicolumn{2}{|c|}{38} & - & - & 7 & 100 \\
\hline & Right & 51 & \multicolumn{2}{|c|}{43} & - & - & 6 & 100 \\
\hline \multicolumn{2}{|l|}{ Trunk } & 52 & 38 & 3 & - & - & 6 & 100 \\
\hline \multirow{2}{*}{\multicolumn{2}{|c|}{ Lower extremity }} & Standing & $\begin{array}{l}\text { Standing with } \\
\text { bending knee }\end{array}$ & Walking & Sitting & Etc. & Invisible & \\
\hline & & 12 & 4 & 33 & 48 & - & 3 & 100 \\
\hline
\end{tabular}


Table 6. Work posture distribution(\%) of patrolling

\begin{tabular}{|c|c|c|c|c|c|c|c|c|}
\hline \multicolumn{2}{|c|}{ Upper extremity } & Neutral & \multicolumn{2}{|c|}{ Bending } & Twisting & Bending \& Twisting & Invisible & Total \\
\hline \multicolumn{2}{|l|}{ Neck } & 61 & \multicolumn{2}{|c|}{16} & 6 & 3 & 14 & 100 \\
\hline \multirow{2}{*}{ Upper arm } & Left & 77 & 9 & - & - & - & 14 & 100 \\
\hline & Right & 79 & 8 & - & - & - & 13 & 100 \\
\hline \multirow{2}{*}{ Lower arm } & Left & 76 & \multicolumn{2}{|c|}{6} & - & - & 18 & 100 \\
\hline & Right & 72 & \multicolumn{2}{|c|}{12} & - & - & 16 & 100 \\
\hline \multirow{2}{*}{ Hand } & Left & 81 & \multicolumn{2}{|c|}{4} & - & - & 15 & 100 \\
\hline & Right & 85 & \multicolumn{2}{|c|}{3} & - & - & 12 & 100 \\
\hline \multicolumn{2}{|l|}{ Trunk } & 86 & 4 & 1 & - & - & 9 & 100 \\
\hline \multirow{2}{*}{\multicolumn{2}{|c|}{ Lower extremity }} & Standing & $\begin{array}{l}\text { Standing with } \\
\text { bending knee }\end{array}$ & Walking & Sitting & Etc. & Invisible & \\
\hline & & 14 & - & 80 & - & - & 6 & 100 \\
\hline
\end{tabular}

Table 7. Work posture distribution(\%) of security

\begin{tabular}{|c|c|c|c|c|c|c|c|c|}
\hline \multicolumn{2}{|c|}{ Upper extremity } & Neutral & \multicolumn{2}{|c|}{ Bending } & Twisting & Bending \& Twisting & Invisible & Total \\
\hline \multicolumn{2}{|l|}{ Neck } & 52 & \multicolumn{2}{|c|}{22} & 19 & - & 7 & 100 \\
\hline \multirow{2}{*}{ Upper arm } & Left & 34 & 60 & 0 & - & - & 6 & 100 \\
\hline & Right & 42 & 52 & 0 & - & - & 6 & 100 \\
\hline \multirow{2}{*}{ Lower arm } & Left & 23 & \multicolumn{2}{|c|}{71} & - & - & 6 & 100 \\
\hline & Right & 34 & \multicolumn{2}{|c|}{60} & - & - & 6 & 100 \\
\hline \multirow{2}{*}{ Hand } & Left & 67 & \multicolumn{2}{|c|}{27} & - & - & 6 & 100 \\
\hline & Right & 59 & \multicolumn{2}{|c|}{35} & - & - & 6 & 100 \\
\hline \multicolumn{2}{|l|}{ Trunk } & 34 & 59 & 0 & - & - & 6 & 100 \\
\hline \multirow{2}{*}{\multicolumn{2}{|c|}{ Lower extremity }} & Standing & $\begin{array}{l}\text { Standing with } \\
\text { bending knee }\end{array}$ & Walking & Sitting & Etc. & Invisible & \\
\hline & & 4 & - & 1 & 88 & - & 7 & 100 \\
\hline
\end{tabular}

Table 8. Work posture distribution(\%) of cleaning

\begin{tabular}{|c|c|c|c|c|c|c|c|c|}
\hline \multicolumn{2}{|c|}{ Upper extremity } & Neutral & \multicolumn{2}{|c|}{ Bending } & Twisting & Bending \& Twisting & Invisible & Total \\
\hline \multicolumn{2}{|l|}{ Neck } & 50 & \multicolumn{2}{|c|}{42} & 3 & 3 & 2 & 100 \\
\hline \multirow{2}{*}{ Upper arm } & Left & 75 & 22 & 0 & - & - & 3 & 100 \\
\hline & Right & 49 & 49 & 0 & - & - & 2 & 100 \\
\hline \multirow{2}{*}{ Lower arm } & Left & 16 & \multicolumn{2}{|c|}{82} & - & - & 2 & 100 \\
\hline & Right & 36 & \multicolumn{2}{|c|}{62} & - & - & 2 & 100 \\
\hline \multirow{2}{*}{ Hand } & Left & 6 & \multicolumn{2}{|c|}{91} & - & - & 3 & 100 \\
\hline & Right & 3 & \multicolumn{2}{|c|}{94} & - & - & 3 & 100 \\
\hline \multicolumn{2}{|l|}{ Trunk } & 59 & 25 & 10 & 3 & - & 3 & 100 \\
\hline \multirow{2}{*}{\multicolumn{2}{|c|}{ Lower extremity }} & Standing & $\begin{array}{l}\text { Standing with } \\
\text { bending knee }\end{array}$ & Walking & Sitting & Etc. & Invisible & \\
\hline & & 27 & 14 & 57 & - & - & 2 & 100 \\
\hline
\end{tabular}


단위 작업별로 분석한 작업 자세분석 결과는 Table 6 8 과 같다. 순찰 작업은 모든 상체 부위에서 중립 자세의 비율 이 높게 나타났으며, 하지는 걷기 자세가 하루 순찰시간 중 $80 \%$ 를 차지하였다(Table 6). 상황 작업의 경우 위팔(좌: $60 \%$, 우: $52 \%$ ), 아래팔(좌: $71 \%$, 우: $60 \%$ ), 허리의 굴곡 이 높은 비율을 나타냈다. 하지는 하루 순찰시간의 $88 \%$ 가 앉기 자세를 나타냈다(Table 7). 청소 작업은 작업시간 중 목은 $50 \%$ 가 중립 자세를 나타냈으며, $42 \%$ 가 굴곡 자세를 나타냈다. 왼쪽 위팔은 $75 \%$ 가 중립 자세를 나타냈으며, 오 른쪽 위팔은 중립, 굴곡 자세의 비율이 동일하게 $49 \%$ 를 나 타냈다(Table 8).

\section{Discussion}

경비직 작업자를 대상으로 작업분석을 실시한 결과, 크게 순찰, 상황, 대기, 청소로 단위 작업을 구분하였다. 경비 작 업자의 일일 근무시간(8시간 기준) 중 상황 작업은 $60.8 \%$ 를 차지한다. 다음으로 청소 작업은 $26.5 \%$ 의 비율을 차지한 다. 상황 작업은 경비/상황실 내에서 정적인 좌식상태로 상 황을 보며 대기하는 작업이다. 이처럼 경비직 작업자들은 일 일 근무시간 중 대부분의 시간을 좁은 공간에 앉아서 상황 업무를 보기 때문에 의자에서 장시간 정적으로 앉은 자세가 지속된다. 이와 같은 이유로 각 신체 부위 중 목, 위팔, 손은 중립 자세, 아래팔은 책상 위에 얹은 굴곡 자세가 많이 발생 한다. 하지 부위는 상황과 순찰 업무로 인해 걷기와 앉기의 자세가 높은 비율로 나타났다. 경비직 작업자의 주요 업무는 순찰, 상황이다. 그 외 부가적으로 발생하는 업무인 분리수 거, 청소 등의 미화 업무는 매일 발생하지 않으며 필요 시에 만 간헐적으로 발생한다. 종합적으로 경비직 작업자들의 작 업강도가 크지 않아 신체적으로 큰 무리는 주지 않는다고 판단된다.

자세분석의 종합적인 결과를 살펴보면, 상체 부위는 아래 팔을 제외한 나머지 부위들은 중립 자세가 높은 비율을 나 타냈으며 하지의 경우에는 앉기와 걷기가 $79 \%$ 의 비율을 차지하였다. 다른 신체 부위와 달리 아래팔의 경우 굴곡의 비율이 높게 나타난 이유는 경비 작업자들이 대부분의 시간 을 경비초소 내의 책상 앞에 앉아서 상황 업무를 보기 되기 때문이다. 이는 작업자의 대부분이 상황 업무를 볼 때 책상 이나 의자의 팔걸이 위에 팔꿈치를 기대고 있기 때문에 굴 곡의 비율이 높게 나타난 것으로 예상된다.

경비 작업자들은 대게 높은 연령층으로 구성되어 있으며 작업 자체에서 기인하는 육체적인 작업부하가 크지는 않았 지만, 경비라는 직업의 특성상 불규칙적인 생활주기(1일 근
무, 1 일 비번)와 경비/상황실이라는 한정된 공간에서의 숙 식해결에 따른 불편함과 주민들의 민원처리로 인하여 정 신적인 스트레스가 가중되는 것으로 파악된다. Kim et al. (1999)은 경비직 작업자는 고령이 가지는 공통된 건강상의 문제 외에 교대근무, 좁은 공간에서의 근무에 의해 문제가 발생할 수 있다고 한다. 교대 작업이 건강에 미치는 영향은 잠들기 어렵거나, 수면부족, 수면상태불량, 위염, 소화성궤양, 변비 등의 질환 및 증상의 유발율이 높은 것으로 알려져 있 다(Gordon et al. 1986). 또한 Knutsson et al.(1986)은 교대근무의 기간이 길어질수록 심혈관계 질병 발생위험도가 커진다고 하였다. 이처럼 몇몇 연구에서 경비직 작업자에 대 하여 교대근무의 문제성과 그로 인하여 도래되는 건강상의 문제를 야기하고 있다.

Kim et al. (1999)의 연구에서도 경비직 작업자는 정신을 집중한 육체적 작업이 거의 없다고 하였다. 본 연구의 결과 에서도 마찬가지로 작업으로 인한 강도는 크지 않았다. 그 로 인하여 경비직 작업은 신체적으로 큰 무리를 주지 않는 다는 결론을 도출하였다. 하지만 위의 서론에서도 이야기 했 듯이 경비직에 근무하는 대다수가 고령 근로자이다. 고령 근 로자는 근골격계질환 발생율이 높은 고위험군으로서 작업환 경과 작업방법의 개선으로 예방을 위한 선 조치가 필요하다.

이를 위하여, 경비/상황실의 제한된 공간의 설계에 있어 서 작업자의 자세를 변경함에 불편함이 없도록 충분한 공 간을 확보할 것을 권장한다. 이는 작업자가 균형 잡힌 다양 한 자세를 선택할 수 있으며, 사용근육수의 증가로 부하가 고르게 분배되는 효과를 야기한다(Korea Ministry of Labor and Korea Occupational Safety \& Health Agency, 2008-24-908). 또한 대부분의 시간을 책상 앞에 앉아 있는 경비 작업자들은 책상의 높이와 의자의 등받이가 적절 하지 않다면 등과 허리의 신체 부위에 부담을 줄 가능성이 높다. 따라서 의자는 무릎관절의 각도가 $90^{\circ}$ 전 · 후가 되도 록 조절가능 해야 하며 팔걸이가 있는 의자와 책상 하단에는 충분한 공간을 확보함으로써 자세 제한에 대한 부담을 감소 시킬 수 있을 것이다.

경비직 작업자들에게서 발생하는 순찰 작업은 걷기 자세 가 높은 비율로 발생함으로 하지 쪽의 부하는 필연적일 것 이다. 따라서 복장규정상 착용하는 구두 대신 편한 신발인 운동화나 등산화로 대체하는 방법을 고려해야 할 것이다. 추 가적으로 신발 밑창에 피로 방지용 내충격성 재질의 인솔 (insole)을 착용하게 하여 딱딱한 바닥 및 구두 밑창에서 오는 직접적인 영향을 감소시킬 수 있다(OHCOW, 2005). 그리고 구두의 착용 시 뒤꿈치는 고정시키되, 발가락은 자유 롭게 움직일 수 있는 공간을 마련하여 발가락의 통증과 피로 를 감소시킬 것을 권장한다(OHCOW, 2005).

본 연구는 근골격계질환 발생 위험이 높은 고령 근로자가 
다수 분포한 경비직 작업자를 대상으로 인간공학적 평가 방 법을 사용하여 작업을 평가하였다. 연구의 제한점은 특정 장 소의 작업자를 대상으로 현장조사를 실시한 점과 연구대상 의 수가 다수 부족하다는 것이 미흡한 점으로 판단된다. 또 한 자세분석의 경우 인접 체절 간의 상호관계를 고려하지 못했다. 예를 들면 허리의 굴곡이 발생할 경우 위팔의 경우 중립 자세가 오히려 불편한 자세가 될 수 있다. 이러한 특성 을 고려한 추후 연구가 필요할 것이다.

향후 진행되어야 할 연구로는 경비직 외의 고령 근로자의 취업 분포가 높은 직종에 대한 인간공학적인 평가가 이루어 져야 할 것으로 예상된다. 또한 실질적인 개선을 위하여 인 간공학적으로 개선된 도구 개발 및 작업환경, 작업방법에 대 한 연구를 진행해야 할 것이다.

\section{References}

Aday, L. A., AT RISK IN AMERICA: The health and health care needs of vulnerable populations in the United States $2^{\text {nd }}$ ed. JOSSEY-Bass, A Wiley Company, San Francisco, USA, 2001.

An, T. H., Kim, J. S. and Jeong B. Y., Ergonomic job hazard assessment of hotel chef, Journal of the Ergonomics Society of Korea, 25(3), 105 $-111,2006$.

Andrewa, D. M. and Callaghan, J. P., Determining the minimum sampling rate needed to accurately quantify cumulative spine loading from digitized video, Applied Ergonomics, 34(6), 589-595, 2003.

Baty, D. and Stubbs, D. S., Postural stress in geriatric nursing, International Journal of Nursing Studies, 24(4), 339-344, 1987.

Choi, W. I., Kim, D. S., Kim, J. H., Choi, D. S., Kim Y. W., Kim J-H. and Kang S-K., A survey for status of the work-related musculoskeletal disorders in the food \& accommodation industry, Proceedings of the Ergonomics Society of Korea Conference, pp. 279-285, 2007.

Gordon, N. P., Cleary, P. D., Parker, C. E. and Czeisler, C. A., The prevalence and health impact of shiftwork, Am J Health, 76(10), 1225-1228, 1986.

Grandgean, E. and Hunting, W., Ergonomics of posture-Review of various problems of standing and sitting posture, Applied Ergonomics, 8(3), 135-140, 1777.

Haight, J. E. and Belwal, U., Designing for an Aging workforce, Professional safety, 20-33, 1993.

Hagner, I. M. and Hagberg, M., Evaluation of two floor-mopping work methods by measurement of load, Ergonomics, 32(4), 401-408, 1989.

Jung-Choi, K-H., Lee, S-Y., Ki, M., Cho, K-H., Kang, H-T., Kwon, Y-J., Kim, H-J., Kim, M-H., Min, K-B., Park, H-S., Kim, J-Y., Ha, E-H. and Paek, D-M., Multilevel analysis of risk factors related to musculoskeletal symptoms among caterers for elementary school lunch services, Korea Journal of Occupational Environment Medicine, $16(4), 436-449,2004$
Kang, S-H., Kim, H. J., Kim, Y. K. and Koo, J-W., Effectiveness and factor associated with the control of hypertension in apartment management workers- Provided with occupational health services-, Korea Journal of Occupational Environment Medicine, 14(4), 426-435, 2002.

Karhu, O., Kansi, P. and Kuorinka, I., Correcting working postures in industry: a practical method for analysis, Applied Ergonomics, 8(4), $199-201,1977$.

Keyserling, W. M., Postural analysis of trunk and shoulders in simulated real time, Ergonomics, 29(4), 569-583, 1986.

Keyserling, W. M., Computer-aied posture analysis of the trunk, neck, shoulders and lower extremities, Taylor \& Francis, London, 1990.

Keyserling, W. M., Brouwer, M. and Silverstein, B. A., A checklist for evaluation ergonomic risk factors resulting from awkward postures of the legs, trunk and neck, International Journal of Industrial Ergonomics, 9(4), 283-301, 1992.

$\mathrm{Kim}, \mathrm{J}-\mathrm{H}$., The qualitative study on the triggering factors of private security guards' stress, Korea Security Science Association, 15, 89-105, 2008.

Kim, S. K., Sakon, J., Chung J. H., Kim, C. H., Bae, S. K. and Jang, Y. J., Health of apartment guards and associated factors, Yeungnam University Journal of Medicine, 16(2), 357-363, 1999.

Korea Ministry of Labor, Investigation of economically active population (old worker), 2006

Korea Ministry of Labor, http://www.kosis.kr/, 2009.

Korea Ministry of Labor and Korea Occupational Safety \& Health Agency, 2008-24-908, Health guide for standing worker, 2008.

Korea Employment Information Service, The major job occupational of old worker, 2004.

Knutsson, A., Akerstedt, T., Jonsson, B. G. and Orth-Gomer, T., Increased risk of ischemic heart disease in shift workers, The Lancet July 12 89-92, 1986.

Kumar, R., Chaikumarn, M. and Kumar, S., Physiological, subjective and postural loads in passenger train wagon cleaning using a conventional and redesigned cleaning tool, International Journal of Industrial Ergonomics, 35(10), 931-938. 2005.

Kumar, R. and Kumar, S., Musculoskeletal risk factors in cleaning occupation-A literature review, International Journal of Industrial Ergonomics, 38(2), 158-170, 2008.

Lee, H. K., Myong, J. P., Jeong, E. H., Jeong, H. S. and Koo, J-W., Ergonomic workload evaluation and musculo-skeletal symptomatic features of street cleaners, Journal of the Ergonomics Society of Korea, 26(4), 147-152, 2007.

Lee, I-S., Chung, M-K. and Kee, D-H., Evaluation of postural load of varying leg postures using the psychophysical scaling, Journal of the Ergonomics Society of Korea, 21(4), 47-65, 2002.

Lee, K. Y., Park, J. S., Moon, Y. H., Lee, G. H., Choi, S. W., Lee, N. R., Kim, M. S. and Oh, J. Y., Analysis of industrial accident vulnerable populations, Korea Occupational Safety \& Health Research Institute, 2006-85-785, 2006.

Messing, K. and Kilbom, A., Standing and very slow walking: foot pain-pressure threshold, subjective pain experience and work activity. Applied Ergonomics, 32(1), 81-90, 2001.

Menz, H. B., Lord, S. R. and Fitzpatrick R. C., Age-related differences in 
walking stability, Age and Ageing, 32, 137-142, 2003.

Myong, J. P., Lee, H. K, Kim, H. R., Jeong, H. S., Jeong, E. H., Nam, W. and K, J-W., Musculo-skeletal systems municipal sanitation workers and ergonomic evaluation on upperlimb, Korea Journal of Occupational Environment Medicine, 20(2), 93-103, 2008

OHCOW, Occupational health clinics for Ontario workers Inc. - Working on your feet, http://www.Ohcow. on. ca/resources/handbook, 2005.

Ono, Y., Shimaoka, M., Hiruta, S. and Takeuchi, Y., Low back pain among cooks in nursery schools, Industrial Health, 35(2), 194-201, 1997.

Ryan, G. A., The prevalence of musculo-skeletal symptoms in supermarket workers, Ergonomics, 32(4), 359-371, 1989.

Sebastian, J. G. and Bushy, A., Special populations in the community: Advances in reducing health disparities. Gaithersburg, MD: Aspen Publishers, 1999.

Wegman D. H. and McGee J. P., Health and safety needs of older worker, National Research Council, 2004.

Woods, V. and Buckle, P., Musculoskeletal ill health amongst cleaners and recommendations for work organisational change, International Journal of Industrial Ergonomics, 36(1), 61-72, 2005.

\section{Author listings}

\section{Kyung-Sun Lee: 1ks79s@ajou.ac.kr}

Highest degree: M.S., Department of Industrial and Information Systems Engineering, Ajou University

Position title: $\mathrm{PhD}$. Candidate, Department of Industrial and Information Systems Engineering, Ajou University

Areas of interest: Ergonomics, Hand Biomechanics, Work Design

Inseok Lee: lis@hknu.ac.kr

Highest degree: Ph.D., Department of Industrial Engineering, POSTECH Position title: Professor, Department of Safety Engineering, Hankyong National University

Areas of interest: Ergonomics in Safety and Health, Agricultural Ergonomics, Accessible Design
Hyunjoo Kim: kuffs@dku.edu

Highest degree: $\mathrm{PhD}$, Department of preventive medicine, Hanyang University

Position title: Associated professor, Department of occupational and environmental medicine, Dankook University

Areas of interest: Musculoskeletal disorders

Kyunghee Jung-Choi: jungchoikh@gmail.com

Highest degree: M.D., PhD., Department of Preventive Medicine, Ulsan University

Position title: Assistant Professor, Department of Preventive Medicine, Ewha Womans University School of Medicine

Areas of interest: Health inequalities, work-related disease

\section{Jinwook Bahk: azrael@snu.ac.kr}

Highest degree: MPH, Department of Occupational \& Environmental Health, School of Public Health, Seoul National University Position title: $\mathrm{PhD}$. Candidate, Department of Occupational \& Environmental Health, School of Public Health, Seoul National University Areas of interest: Ergonomics, Job stress, Health inequity

Myung-Chul Jung: mcjung@ajou.ac.kr

Highest degree: Ph.D., Department of Industrial Engineering, Pennsylvania State University

Position title: Associate Professor, Department of Industrial and Information Systems Engineering, Ajou University

Areas of interest: Work design, ergonomics, product development

Date Received : 2011-04-04

Date Revised : 2011-05-24

Date Accepted : 2011-05-28 